\title{
Dimensional stability of materials subject to random vibration
}

\author{
R.L. Edeson ${ }^{\mathrm{a}, *}$, G.S. Aglietti ${ }^{\mathrm{b}}$, A.R.L. Tatnall ${ }^{\mathrm{b}}$ \\ a RAL Space, STFC Rutherford Appleton Laboratory, Chilton, Didcot, Oxfordshire OX11 0QX, United Kingdom \\ ${ }^{\mathrm{b}}$ School of Engineering Sciences, University of Southampton, Highfield, Southampton, SO17 1BJ, United Kingdom
}

\section{A R T I C L E I N F O}

\section{Article history:}

Received 25 June 2012

Received in revised form

20 September 2012

Accepted 1 October 2012

Available online $\mathrm{xxx}$

\section{Keywords:}

Dynamics

Cyclic loading

Mechanical testing

Finite elements

\begin{abstract}
A B S T R A C T
High precision stable structures are potentially vulnerable to dimensional instability induced by exposure to random vibration. There appears to have been little work in the literature to understand or mitigate structural dimensional instability induced by random vibration. To gain more insight into this issue, a novel test was recently developed to assess the plastic strain response in the $10^{-5}$ to $10^{-6}$ range for structural materials subjected to specific random vibration loads. The test was based on a four-point bending configuration with an applied random base excitation. Two types of material were tested - an $\mathrm{Al}$ alloy and a CFRP. This paper presents the test setup and results in detail. The Al alloy samples were found to grow slightly in length during testing, due to a small non-symmetry in the applied load. An FEA model of the test setup was solved in the time domain for a sequence of cyclic loads whose amplitude was based on their probability of exceedance in the random environment. This model, using nonlinear kinematic hardening, was able to predict the residual strain response observed during testing with good accuracy. The main implication of this finding is that ultra stable structures subject to random vibration should be assembled in the most strain-free state possible to avoid loss of dimensional stability due to cyclic hardening.
\end{abstract}

\section{Introduction}

High-performance optical bench structures must typically exhibit high levels of dimensional stability to meet system performance requirements. Optical components, aligned precisely in laboratory conditions, must maintain their relative translational and rotational positions to a high level of accuracy to avoid problematic aberrations and defocus during operations in the field. Such structures may be required to survive exposure to significant levels of shock and vibration over their operational lifetimes, without recourse to optical re-alignment. For example, optical structures destined for space use must contend with a brief but harsh period of random vibration during launch, caused by aero-acoustic noise, rocket engine noise and stage separation events. Re-alignment in orbit is not always an option, necessitating the need for structures with highly reliable dimensional stability.

A typical optical bench structure might be required to support a pair of mirrors around $1000 \mathrm{~mm}$ apart, with a positional accuracy of several $10 \mathrm{~s}$ of microns. Thus we are interested in material plastic strain in the $10^{-5}$ to $10^{-6}$ region (as opposed to the $0.2 \%$ more typical of structures with no dimensional stability requirements).

There is a good body of work in the literature on static microyield strength (defined here as the stress at which $10^{-6}$ permanent strain

\footnotetext{
* Corresponding author. Tel.: +4401235445873.

E-mail address: ruben.edeson@stfc.ac.uk (R.L. Edeson).
}

is observed) in metallic materials. An established procedure for investigating microyield behaviour is to apply successive loadunload cycles in increasing increments, measuring the residual strain at the zero-load points between each cycle [1]. Microyield information can be found in the literature for a number of materials used in stable structures [2,3]. Repeated stress cycling above this value may result in a residual strain response dominated by material hardening, an effect that is well understood and relatively easy to model [4]. The literature contains an abundance of hardening data for a range of materials, though mostly in the $0.2 \%$ permanent strain region and above.

For composite materials of interest in stable structures, some work has been done on the effect of stress cycling on dimensional stability, though mainly due to hygrothermal cycling rather than mechanical vibration (for instance [5-7]). Wolff [8] suggests that transverse microcracks in the matrix material are largely responsible for dimensional changes in such circumstances. Nairn [9] points out that the stress induced by thermal cycling is multi-axial (being due to thermal expansivity differences between the constituent materials), while vibration-induced stresses can be uni-axial.

Material yield behaviour can depend on the rate of the applied strain. To test the effect of strain rate, the Hopkinson Bar method has been used for many decades [10], and again there is an abundance of material data (for example, see [11]). However this test applies a single shock pulse, rather than a series of repeated cycles. The time-dependency aspect of composite yield behaviour can be further complicated by viscoelastic strain recovery [12]. 


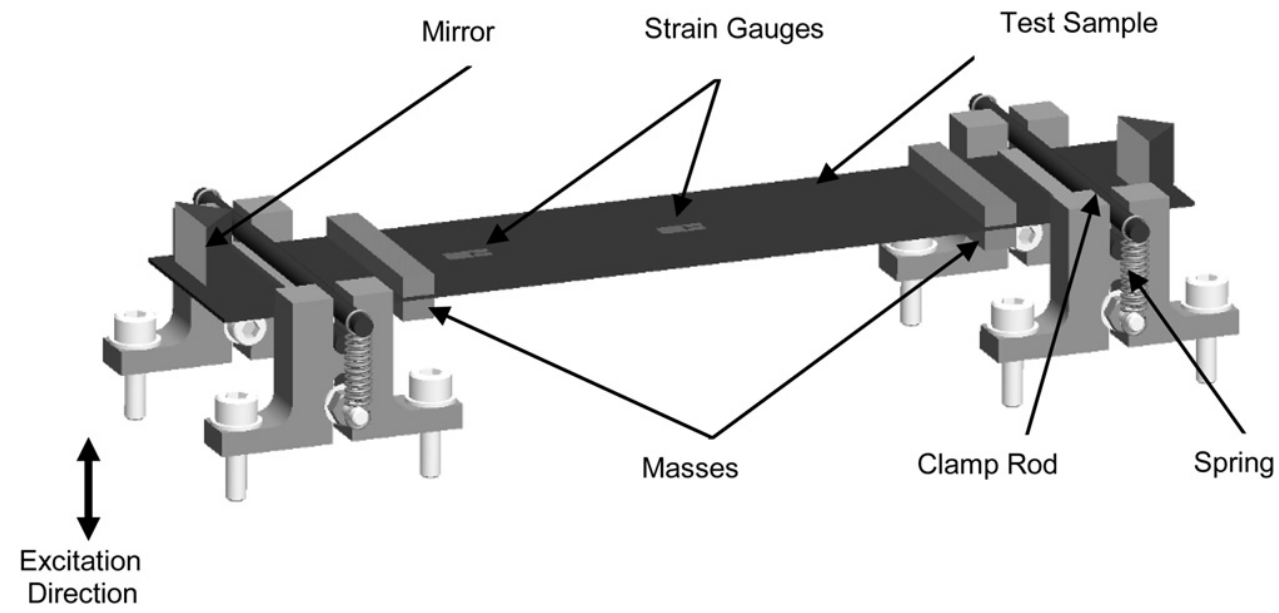

Fig. 1. Test sample support.

For random vibration effects, the literature is mainly concerned with fatigue damage. There are well-established methods for predicting gross failure in materials under cyclic loading using S-N curve data and Miners Cumulative Damage Ratio [13]. However there appears to be a paucity of material data (or procedural methods) for plastic strain in the $10^{-5}$ to $10^{-6}$ region resulting from random cyclic loads.

A structure subject to harmonic excitation is relatively straightforward to analyse. With simple mathematical models (using mass, stiffness and damping parameters), it is possible to deterministically predict stress amplitudes which do not vary from cycle to cycle. Such problems lend themselves to the use of tension-compression cyclic plasticity test data to predict residual strain.

However predicting plastic strain resulting from random vibration can be problematic and there does not yet appear to be an established method for performing these calculations. The difficulties to carry out predictions arise for two reasons. Firstly, it can be difficult to determine a useful stress response to compare with an established yield criterion. The nature of the excitation results in cyclic stresses at a number of different frequencies and amplitudes simultaneously, giving rise to a complex stress state that requires a probabilistic description. It is relatively straightforward to obtain a solution for stress components that are Gaussian with a zero mean. Combining these - to produce a von Mises equivalent resultant for instance - produces a probability distribution that is no longer Gaussian with a zero mean [14], complicating the calculation $[15,16]$.

Secondly, it is not clear how to use such a stress response to predict residual plastic strains. Is the residual strain response dependent on instantaneous high peak stresses that might occur only a few times during the vibration exposure, or is it more likely to depend on lower-amplitude stresses cycles that may occur many thousands of times (or both)? One possible way to tackle this is to use an approach similar to Miner's rule for fatigue analysis, and combine the effects of several stress amplitude levels. The number of cycles of each would be dependent on the probability of exceedance during exposure. This could then be used to approximate a time-history stress response that could be input as sequential load cases in an FEA model that incorporates cyclic hardening. This approach is used later in this paper.

The objectives of this research are to investigate plastic strain behaviour in materials subject to random vibration loading and to asses whether this can be predicted using FEA. The investigation takes a macroscopic view, examining the effects that would typically be of most interest to stable structures practitioners rather than focusing on the microscopic events that cause such effects. A novel test setup has been developed to directly measure the residual strain response in material test samples subject to bursts of random vibration. Two different materials were tested using this setup. This article starts with a detailed description of the test specimens, setup, test procedure and metrology techniques. The results of the test campaign are then discussed in detail. The results for one material are then compared with a finite element model that makes use of nonlinear kinematic hardening with constants based on static test data. The article is concluded with an evaluation of the test and metrology setup, and a summary of the main findings including material behaviour and FEA modelling.

\section{Test setup}

The main goal for the test setup was to simulate the dynamic stress conditions that might typically be seen in a structural element of an optical payload during launch or environmental testing.

The test setup comprised a material sample in strip form, simply supported with a pair of masses inboard from the support points (see Fig. 1). When subject to a random base excitation at the support points, the first modeshape of the samples approximates the deformed shape of a four-point bend test. Three identical samples of each material were tested simultaneously in order to assess result variability. Equivalent static tests were conducted, also in a four-point configuration.

The material samples were flat panels of size $250 \times 50 \mathrm{~mm}$, and $1 \mathrm{~mm}$ thick. Two materials were tested - aluminium alloy $2024 \mathrm{~T} 3$ and a CFRP that is widely used in space instruments. The $\mathrm{Al}$ alloy sample was subject to a stress relief heat treatment $\left(200^{\circ} \mathrm{C} / 1 \mathrm{~h}\right)$. The CFRP used Advanced Composited Group LTM123 cyanate ester resin with M55J fibres. The layup was $\left(0^{\circ}, 90^{\circ}\right.$, and $\left.\pm 45^{\circ}\right)$, and a low-temperature cure cycle was used with a long postcure.

Simple support was achieved by clamping the samples between a pair of cylindrical rods at either end. To avoid damage to the samples at the contact points, aluminium contact pads were bonded to the samples. The pads at one end were made slightly concave in order to prevent the samples from slipping axially during the test. This is shown in Fig. 2. Extension springs (see Fig. 1) were used to impose a constant clamping force of $40 \mathrm{~N}$ at either end. This was determined to be sufficient to prevent gapping at this interface under the highest loads tested.

The masses were bonded-on stainless steel blocks. For the aluminium samples, the masses at either end were $0.050 \mathrm{~kg}$ at either end; for the CFRP samples, they were $0.031 \mathrm{~kg}$. For the aluminium 


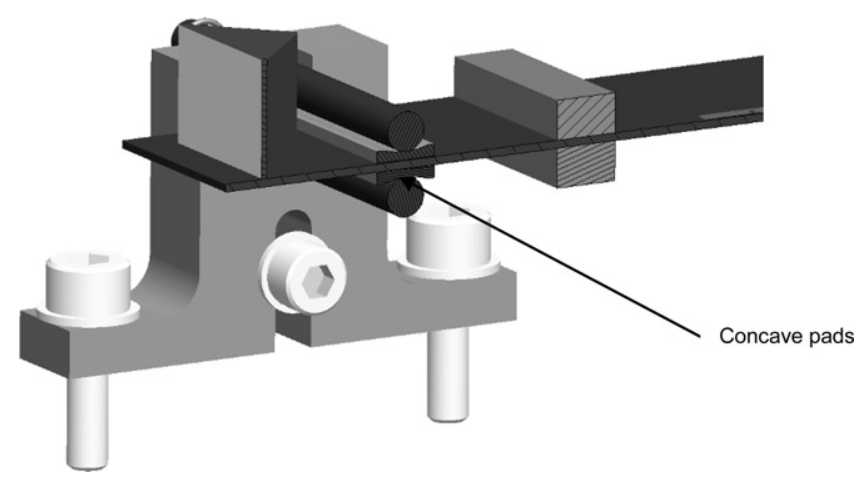

Fig. 2. Cross-section view of clamping rods showing concave contact pads.

samples, the natural frequency was $41 \mathrm{~Hz}$ and for the CFRP it was $81 \mathrm{~Hz}$.

\section{Loads}

A typical random vibration spectrum for a spacecraft instrument qualification test starts with relatively low levels around $20 \mathrm{~Hz}$, with amplitudes rising to peak amplitudes over a plateau of several hundred $\mathrm{Hz}$, then reducing to a final cutoff at $2000 \mathrm{~Hz}$ [17]. This was the form of the input used for these tests.

Finite element analysis was used to predict a spectrum plateau that would initiate observable yield (with observable yield estimated to be $5-20 \mu$ strain initially). For the aluminium samples, the yield criterion was $55 \mathrm{MPa}$ in tension or compression, and was based on a prior static test (discussed in Section 4). For the CFRP sample, the yield criterion was $180 \mathrm{MPa}$ - this was based on results from a breadboard camera structure previously tested by the authors [18]. It was assumed that $3-\sigma$ peak resultants would be sufficient to cause yield. The spectra calculated are shown in Tables 1 and 2.

Initial test runs started at $18 \mathrm{~dB}$ below these baselines. Subsequent test levels were increased in 3 or $6 \mathrm{~dB}$ increments until yield events were observed. It should be noted that the initial response predictions used to generate the baseline spectra were highly dependent on damping assumptions. In reality, damping was higher than expected, at around $6 \%$, as opposed to $2 \%$ for initial calculations. This was almost certainly due to frictional sliding at the mounting points. Therefore input levels that were somewhat higher than the baseline spectra were required to initiate yield.

\section{Static test}

A fourth sample of each material was subjected to static fourpoint bend testing. The test configuration was nominally identical to the dynamic test setup, though with different support structure.

Table 1

Aluminium sample baseline test spectrum (6.44 gRMS).

\begin{tabular}{ll}
\hline Frequency $(\mathrm{Hz})$ & Level \\
\hline $20-30$ & $+3 \mathrm{~dB} / \mathrm{oct}$ \\
$30-200$ & $0.1 \mathrm{~g}^{2} / \mathrm{Hz}$ \\
$200-2000$ & $-5 \mathrm{~dB} /$ oct \\
\hline
\end{tabular}

Table 2

CFRP sample baseline test spectrum (7.66 gRMS).

\begin{tabular}{ll}
\hline Frequency $(\mathrm{Hz})$ & Level \\
\hline $20-70$ & $+3 \mathrm{~dB} /$ oct \\
$70-300$ & $0.1 \mathrm{~g} / \mathrm{Hz}$ \\
$300-2000$ & $-5 \mathrm{~dB} /$ oct \\
\hline
\end{tabular}

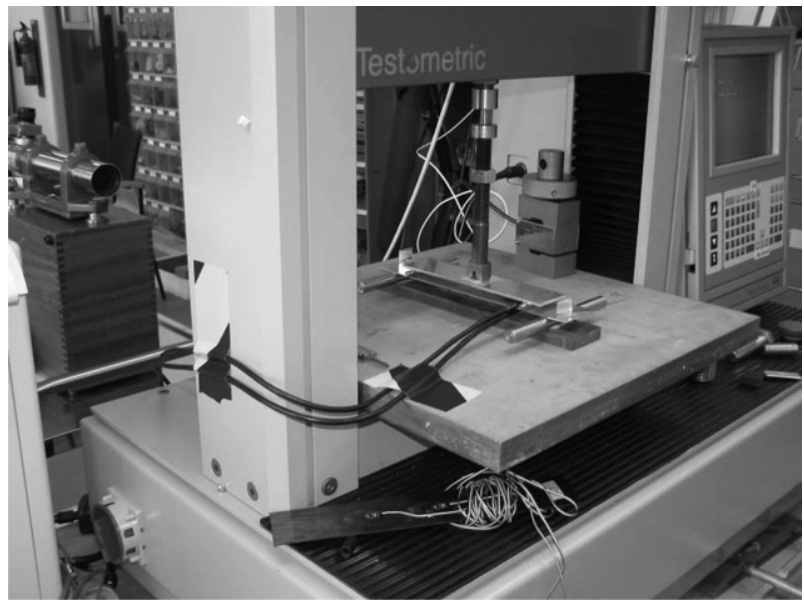

Fig. 3. Static test setup.

Loading was applied at the same locations as the two masses, using a tensile test machine (Fig. 3). The load was cycled, starting with a low load $(5-10 \mathrm{~N})$ and increasing in increments of 5-10 N. Loads were completely relaxed between cycles, and residual strains were recorded at these points. A typical time history for this test is shown in Fig. 4 for a strain gauge on the CFRP sample (the signal was clipped above $1000 \mu$ strain).

\section{Metrology}

The primary method for measuring residual strain was using strain gauges. The instrumentation setup limited the number of strain gauges to two per sample. The Al alloy samples used strain gauges located on the upper and lower surfaces, directly opposed in the centre of the sample. For the CFRP samples, both strain gauges were positioned on the top surface - one in the centre, and one offset towards one of the stainless steel masses (as shown in Fig. 1).

A secondary metrology technique was used to measure the change in curvature of the samples, and hence the residual bending strain. This measurement relied on a pair of parallel flat mirrors bonded to either end of each beam (also shown in Fig. 1). The mirrors were located outside the supports, in a region that was notionally un-stressed by the dynamic response of the strip. The resulting measurement therefore gave an average residual strain over the stressed area, rather than the local measurements provided by the strain gauges. An autocollimator with arcsecond-level accuracy was used to measure this angle before and after each vibration run. The geometry was such that a $1 \mu$ strain average residual strain would produce a tilt of $58^{\prime \prime}$, easily measurable.

\section{Instrumentation}

The CFRP test took place on the $40 \mathrm{kN}$ Ling Dynamic Systems Model 954 MkII. The aluminium samples were tested with a $60 \mathrm{kN}$ LDS V8-440 SPA56K shaker. Acceleration was measured with Bruel \& Kjaer Type 4517 miniature accelerometers.

The strain gauges on the CFRP samples were Vishay CEA-00250UW-350 devices (CTE-matched to the samples). The strain gauges on the aluminium test samples were Vishay CEA-13250UW-350 devices (CTE-matched to aluminium). Both sets of gauges were bonded to the test samples with Vishay M-Bond AE-10 by Vishay Measurements Group UK Ltd. Both sets of gauges were shielded, with shielding termination at the amplifier. For the aluminium samples, the shielding extended to the strain gauge bond wires on the sample, and was additionally terminated at the strain gauge end. For the CFRP samples, shielding only extended as far as 


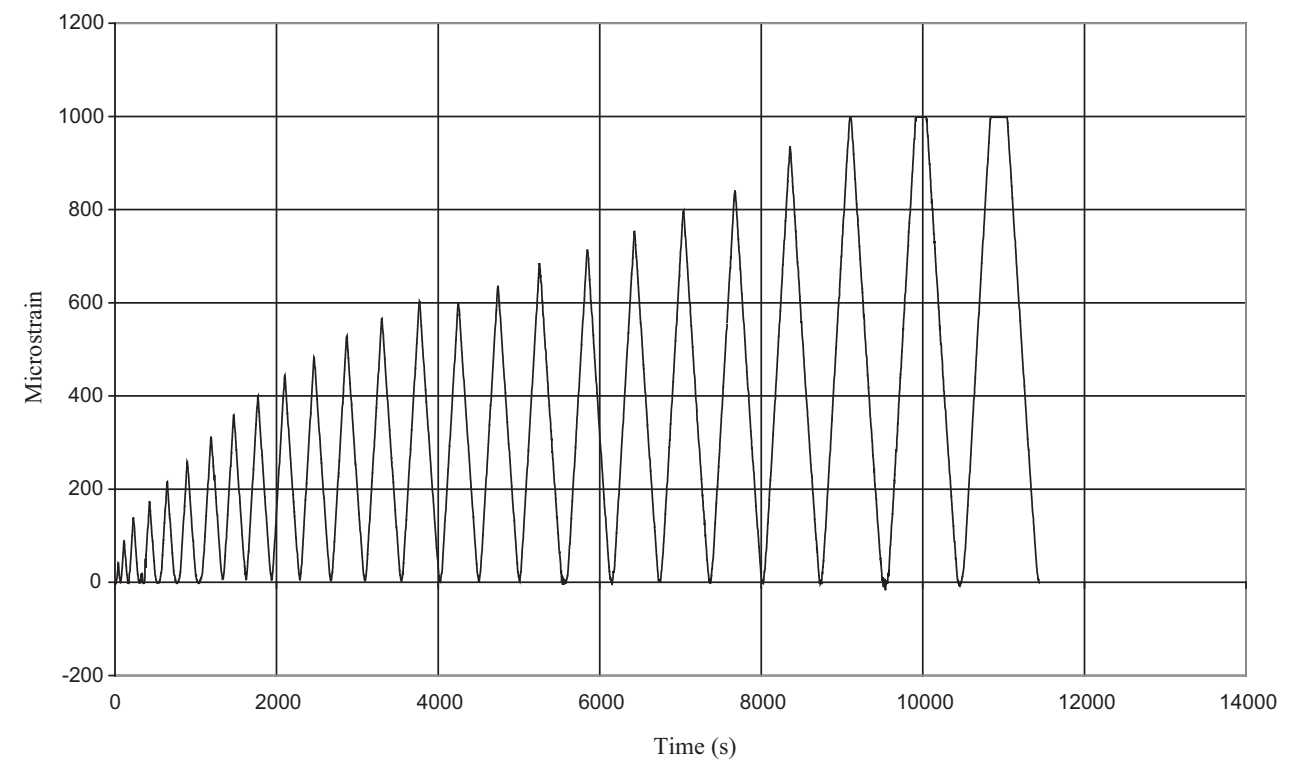

Fig. 4. Strain history for the static test of the CFRP sample.

the test fixture, with the final $150 \mathrm{~mm}$ (approximately) unshielded (see Figs. 5 and 6).

For both test setups, strain gauge amplification was via a Vishay 2200 Signal Conditioning System. All strain gauges were wired in a quarter-bridge configuration. Strain response was measured directly from the 2200 System with a digital voltmeter.

The autocollimator was a Taylor-Hobson Model TA51.

The static test used a Testometric AX500 machine. Strain gauge amplifiers were RDP Electronics model $628 \mathrm{~s}$.

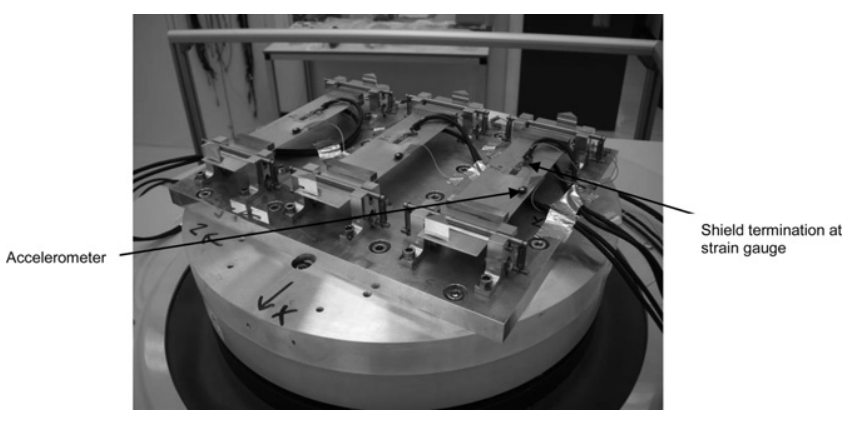

Fig. 5. Aluminium samples on shaker.

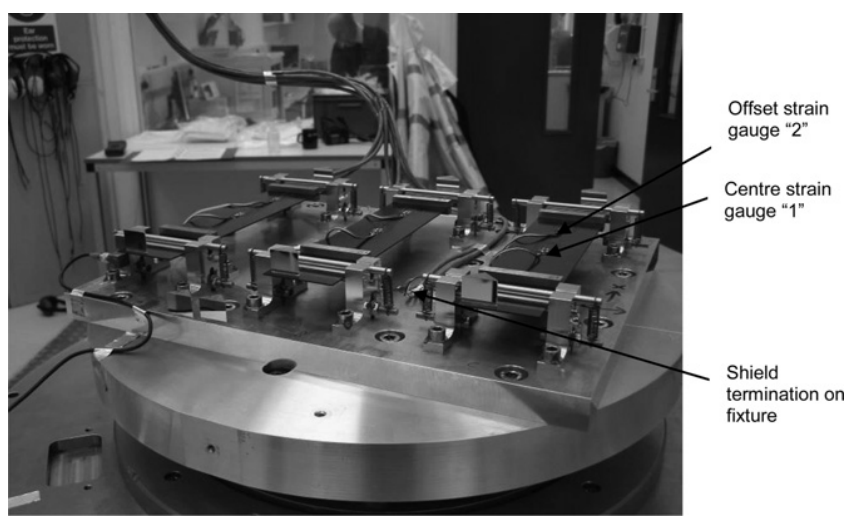

Fig. 6. CFRP samples on shaker (the accelerometers are on the underside of the samples).

\section{Results}

\subsection{Al alloy samples}

The strain gauge results are shown in Fig. 7. These results represent two slightly different test setups. At the end of the first day's testing, it was suspected that experimental error due to clamping forces at the mounting points had been observed. Therefore, a second round of tests was conducted (on the same samples) with the clamping springs removed, and the clamping rods bonded into position. This revised test setup provided no preload on the samples at either end.

All samples show small residual bending strains (up to $\pm 10 \mu$ strain) for the series of tests up to $+6 \mathrm{~dB}$. During the $+12 \mathrm{~dB}$ test, significant movements are seen for all strain gauges. These movements are all in a positive sense, indicating that the samples were exhibiting a tensile residual strain, rather than equal tensile/compressive strains on either side which would indicate pure residual bending. The accelerometer on sample $B$ came loose during this test and was re-bonded for the subsequent $+15 \mathrm{~dB}$ test. The $+15 \mathrm{~dB}$ test lasted only $9 \mathrm{~s}$, though significant additional movements were seen in both net tension and bending on all samples.

Removal of the Clamp Springs had little effect on samples A or B, though appeared to significantly relax the bending strain in sample C. These tests were repeated the following day on samples A and B only, with the Clamp Rods bonded in position and therefore no compressive preload. Both samples were very stable up to the baseline load, when bending strain started to relax in sample B. Sample A showed a large reduction in strain on the bottom strain gauge, which appears to be due to a reduction in both tensile and bending strain.

For results interpretation, the strain gauge measurements were decomposed into bending and tensile components. The residual bending strain was estimated to be half the difference between the top and bottom strain gauge results. This was compared with the autocollimator tilt measurements in Fig. 8. For the first part of the test, the trends in tilt measurement match the trends in bending strain well. For the second part of the test, tilt measurements were only made on sample A, as the mirrors on sample $B$ had become damaged in the $+15 \mathrm{~dB}$ shake. The tilt measurement trend matches the bending strain trend well for sample A during the second round of tests, albeit with an offset of several microstrain. 


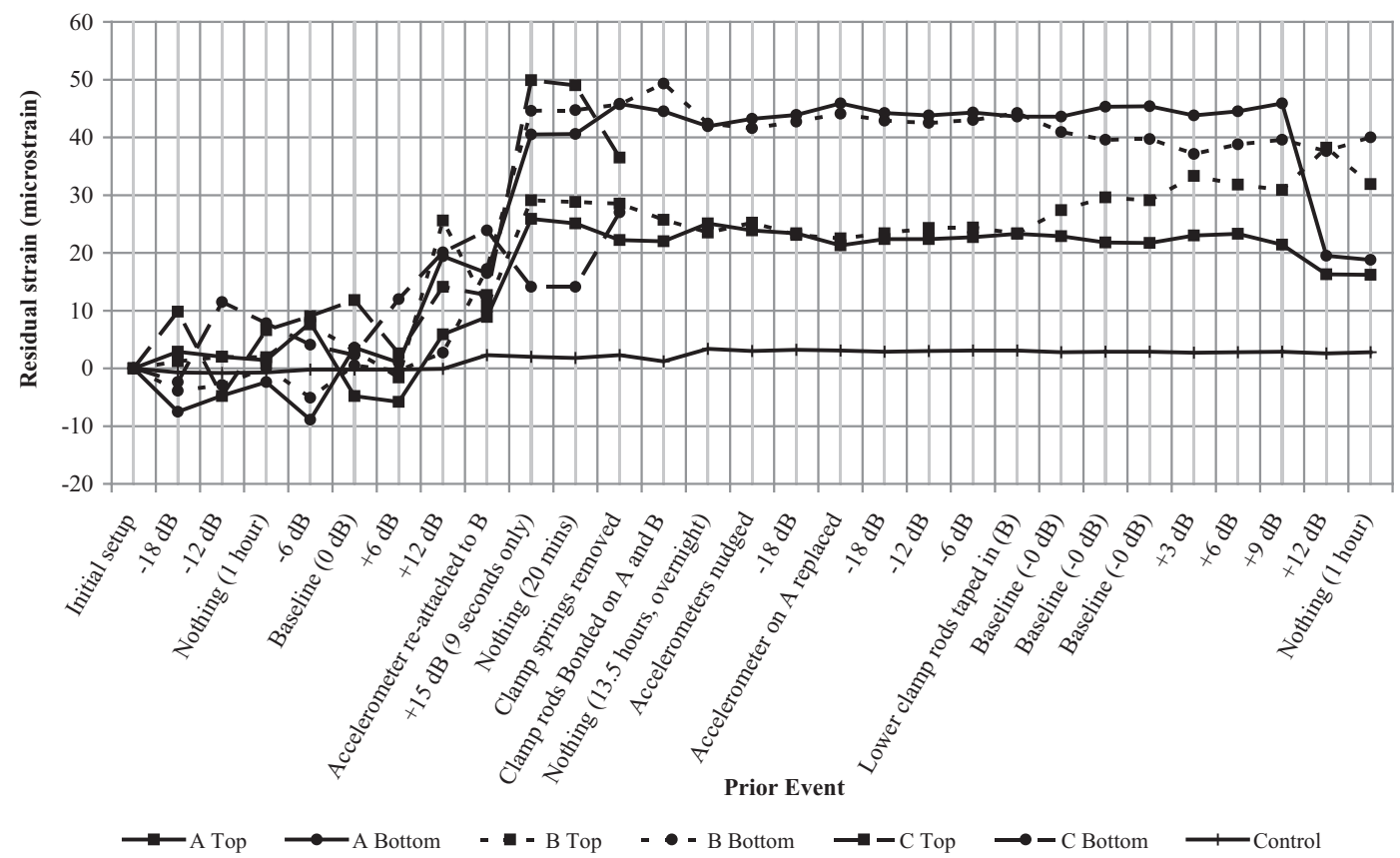

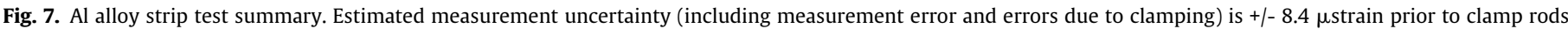
being bonded, and $+/-2.5 \mu$ strain after this.

The residual bending response is presented in a more traditional stress vs. plastic strain format in Fig. 9 for the day 1 tests (using the original test setup). The stress on the vertical axis is RMS stress derived from the RMS strain during vibration, and calculated over the whole frequency range.

The residual bending strains generally increase in magnitude with increasing dynamic stress amplitude - though the sign is not consistent, with changes between tension and compression on subsequent shakes. The mean value of all three is roughly zero for all tests.

The equivalent residual axial strain plot is shown in Fig. 10. Here, residual axial strain is estimated to be simply the average of the upper and lower surface strain gauge results.

These curves display very different behaviour to those of Fig. 9. There is a definite tendency towards residual elongation, with a very similar trend from three samples. This directional response suggests the presence of a non-random factor, such as the presence of pre-stress.

It is interesting to note that an early study by Maringer et al. [19] on microyield in structural materials for space applications found similar behaviour with samples of Al alloy 2024 T4. Two samples

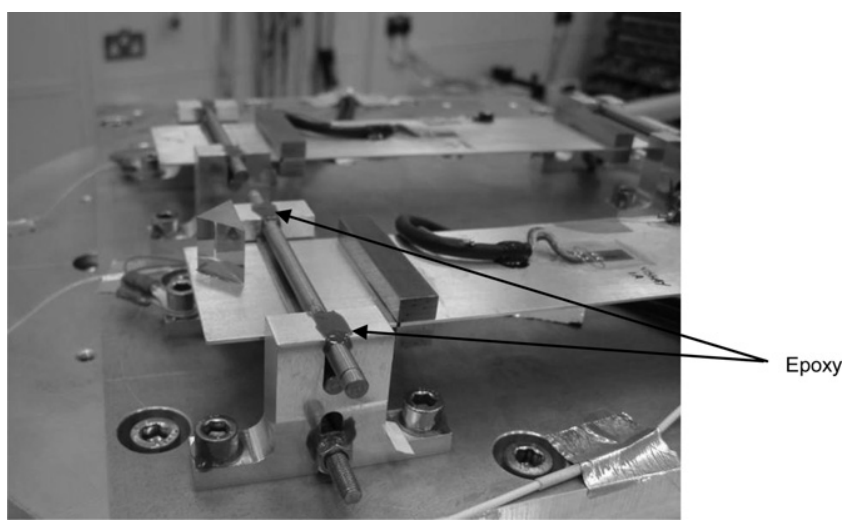

Fig. 8. Clamp springs removed and clamp rods bonded in place. subjected to $10^{6}$ notionally symmetric tension-compression cycles of $\pm 27.6 \mathrm{MPa}$. Both increased in length by over $50 \mu$ strain. The same study also found similar behaviour in titanium and magnesium alloy samples.

\subsection{CFRP results}

Strain gauge and autocollimator results are shown in Figs. 11, 12 and 13 for CFRP samples A, B, and C, respectively. For each strain gauge, " 1 " is the one in the centre, and " 2 " is the off-centre one, as shown in Fig. 6.

The initial strain gauge results are characterised as being noisy, though the noise was reduced following the adddition of shielding to the voltmeter probes used for strain measurement following the $0 \mathrm{~dB}$ (Baseline) shake.

The strain gauge results for samples A and B report similar trends, which are backed-up by the autocollimator tilt measurements. Sample $C$ shows significant discrepancies between all three measurements until after the shielding was added.

Using the tilt results, sample A remains very stable until the $+12 \mathrm{~dB}$ shake; sample $B$ has residual strains imposed during the -3 and $+9 \mathrm{~dB}$ shakes; and sample $C$ is very stable throughout testing. Residual strain is generally low, with the highest measurement being about $25 \mu$ strain. During the final shake, the residual strain in samples A and B reduced.

The strain responses are shown vs. RMS stress in Fig. 14 for the strain gauges mounted centrally on the samples. As both strain gauges were on the same side of the samples the residual strain responses could not be decomposed into bending and axial parts. Also, strain gauge data could not be recorded during dynamic testing, so the RMS stress is derived from accelerometer data from each sample.

Some directional behaviour is evident for samples A and B, which is partially recovered following the final high-level test. Samples A and B follow a similar pattern to each other, while the sample $C$ response is offset from these by about $20 \mu \mathrm{m}$. The peak residual strains seen are less than those seen for the Al alloy samples. 


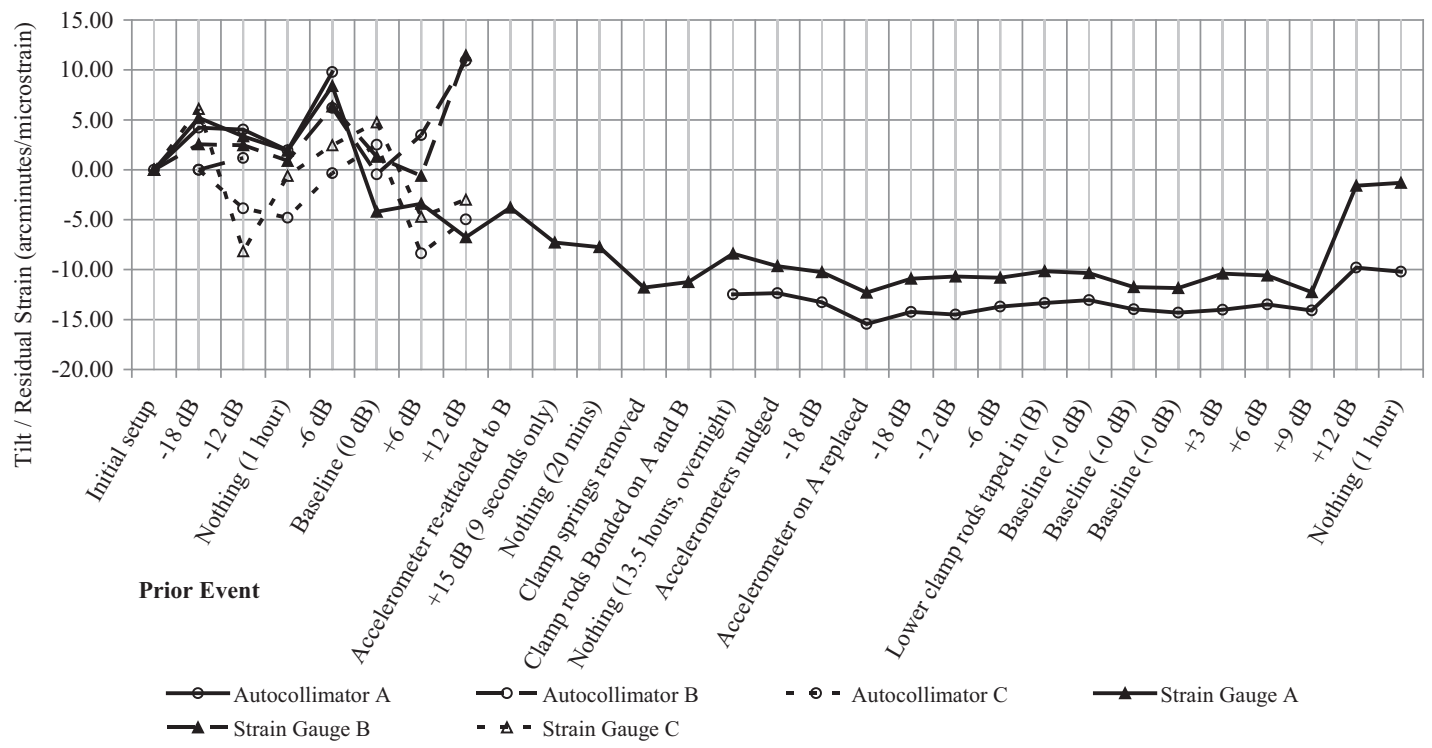

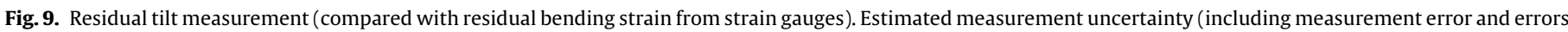
due to clamping) is $+/-6.7$ arcminutes prior to clamp rods being bonded, and $+/-0.8$ arcminutes after this ( 1 arcminute $\sim 1 \mu$ strain).

\section{Error estimation}

Experimental errors were high at the start of these tests, though refinements of the test setup throughout testing are thought to have substantially reduced these.

The CFRP tests were the first ones to be conducted. It was evident from the start of these that electronic noise was a problem. Strain gauge readings fluctuated rapidly by about $\pm 5 \mu$ strain, with occasional excursions of up to $15 \mu$ strain. Several strategies were employed to reduce this, such as suspending the strain gauge leads from an overhead crane, as far as possible from the shaker armature. The most significant reduction in noise came with the addition of shielding to the voltmeter probes used for taking readings. This reduced fluctuations to below $1 \mu$ strain. A summary of the control sample results is shown in Fig. 15.

The Al alloy tests were subsequently performed on an updatedmodel shaker. The strain gauges on these had better shielding, that extended directly to the gauges. The maximum excursion seen on the $\mathrm{Al}$ alloy control sample was $4 \mu$ strain, after the test setup was left overnight.

Strain gauge sensitivity was quoted by the manufacturer as $\pm 0.5 \%$, or about $0.25 \mu$ strain for the maximum values measured here. Strain gauges were thermally matched to the substrate material, and the tests were conducted in a thermal environment that was stable within $3^{\circ} \mathrm{C}$. Taking into account slight mismatches between the strain gauge and substrate CTEs, the maximum possible error due to thermal effects is $\pm 0.3 \mu$ strain for the CFRP test and $\pm 0.45 \mu$ strain for the Al alloy one. It should be noted, however, that temperature (and humidity) fluctuations over the time between metrology runs (several minutes) would have been extremely small.

For the angular measurements, the resolution was about $10^{\prime \prime}$, or about $0.17 \mu$ strain. Other sources of error are the bond layers between the mirrors and the CFRP top layers. A pair of mirrors

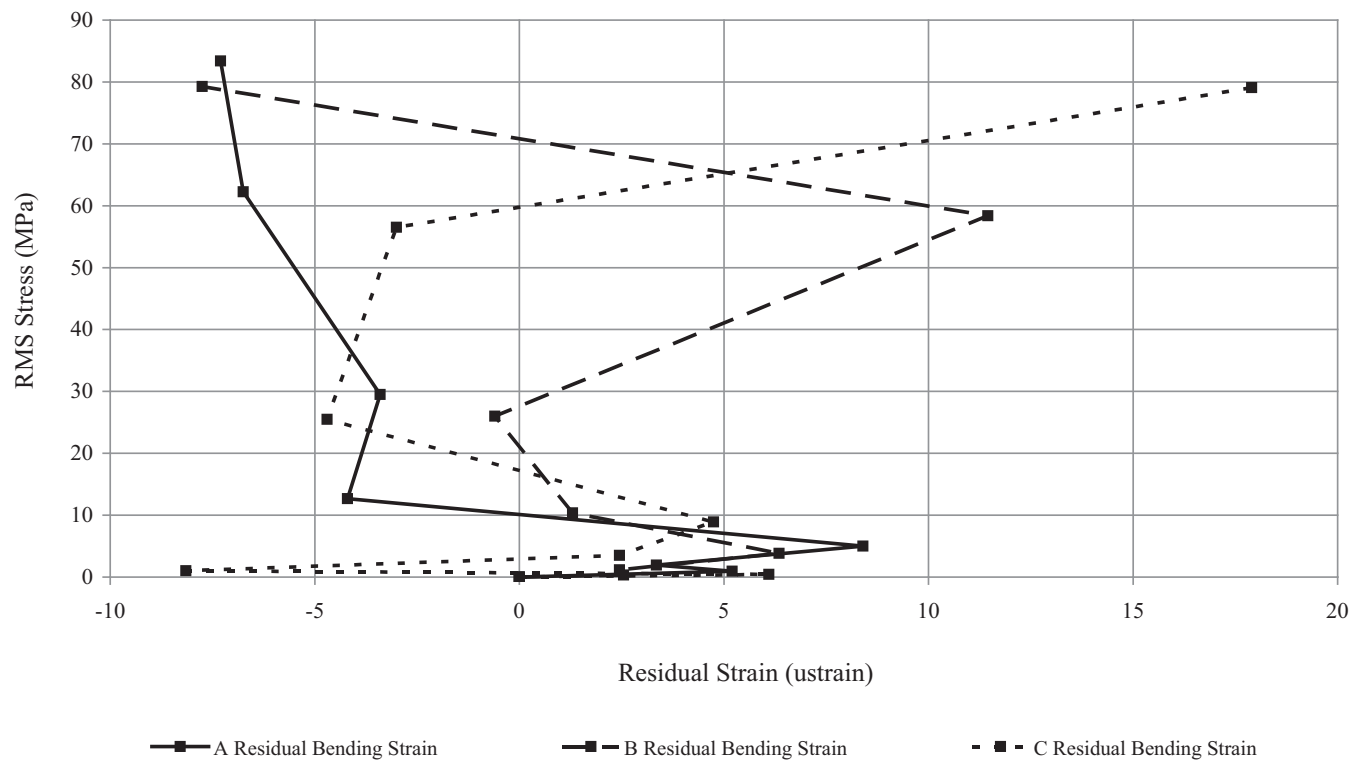

Fig. 10. Al alloy samples: RMS stress vs residual bending strain. 


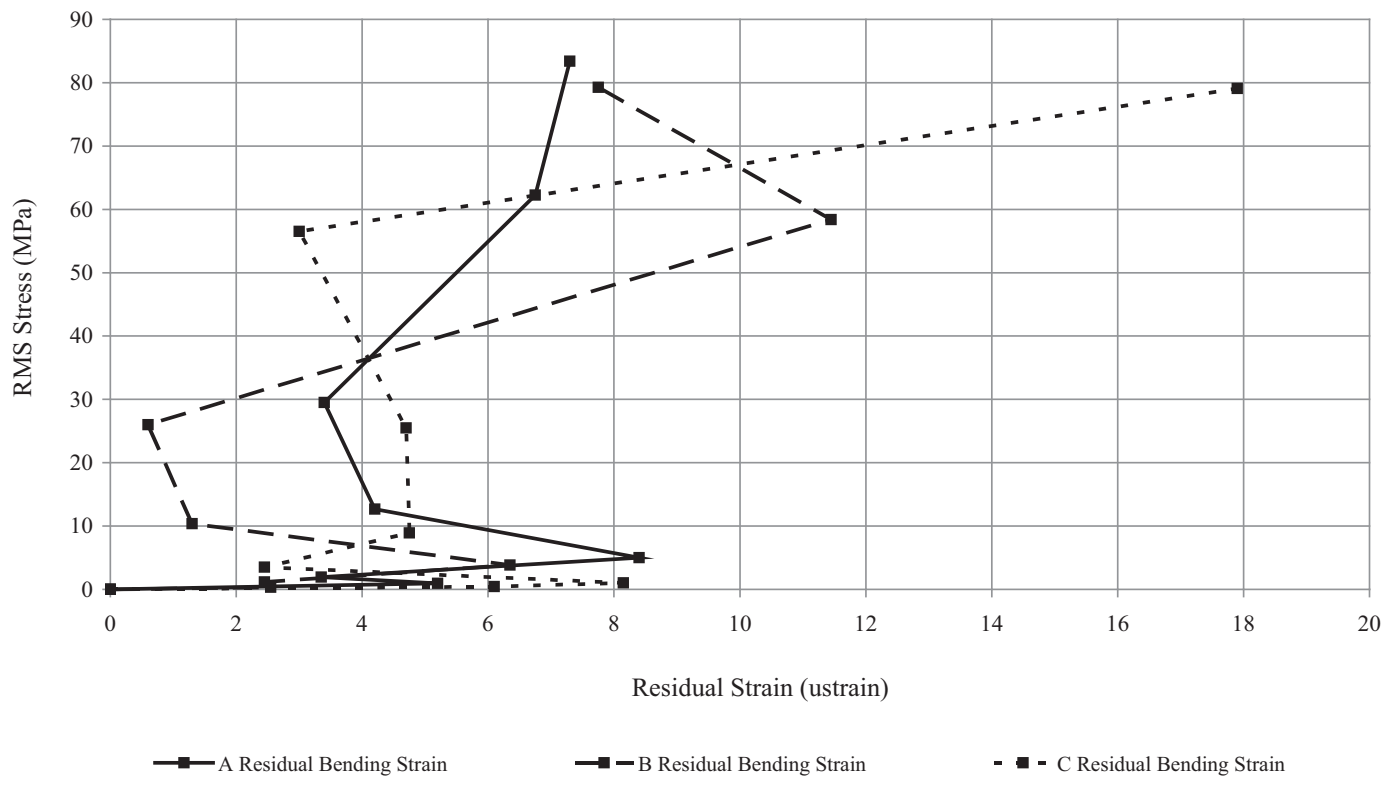

Fig. 11. Al alloy samples: RMS stress vs absolute value of residual bending strain.

was bonded directly to the vibration fixture to assess this (the autocollimator results in Fig. 15). Here, the tilt angle remained at almost exactly zero for the duration of the test, with a peak fluctuation of $0.8^{\prime}$. This may point to a thermal influence. Therefore, it is assumed that the worst-case error observed here is $0.8^{\prime}(\sim 0.8$ average $\mu$ strain).

The other main source of error was from the mounting technique. The test rig undoubtedly produced elastic bending strains in the samples. Application and removal of spring preloads was observed to induce or relax bending strains. To quantify this effect, small bending strains were induced by hand on a sample of each material in a static test setup. The strain induced was enough to induce approximately a $10^{\prime}$ tilt (equivalent to an elastic stress of 0.7 MPa for the Al alloy and 3.1 MPa for the CFRP). The apparent residual deformation was measured with the autocollimator. This was performed three times in each direction, under several mounting configurations. The results are shown in Fig. 16. It is clear that even small perturbations to the test setup can cause apparent residual strains of $13^{\prime}$ for the CFRP, and $8^{\prime}$ for the $\mathrm{Al}$ alloy when the springs are attached. Without the springs, errors are reduced to below $2^{\prime}$ for both.

The final day of dynamic testing of the Al alloy samples made use of this better mounting concept, dispensing with springs and using epoxy to secure the upper Clamp Rods.

\section{Discussion}

\subsection{Test setup}

As discussed, experimental errors were initially high, though the test setup was refined to the point where it was in the $1-2 \mu$ strain region. An alternative method of mounting based on rotary and linear bearings may give even better results, though for more complexity. The correlation between most of the results from the different metrological methods is encouraging. The use of strain gauges was initially problematic in the

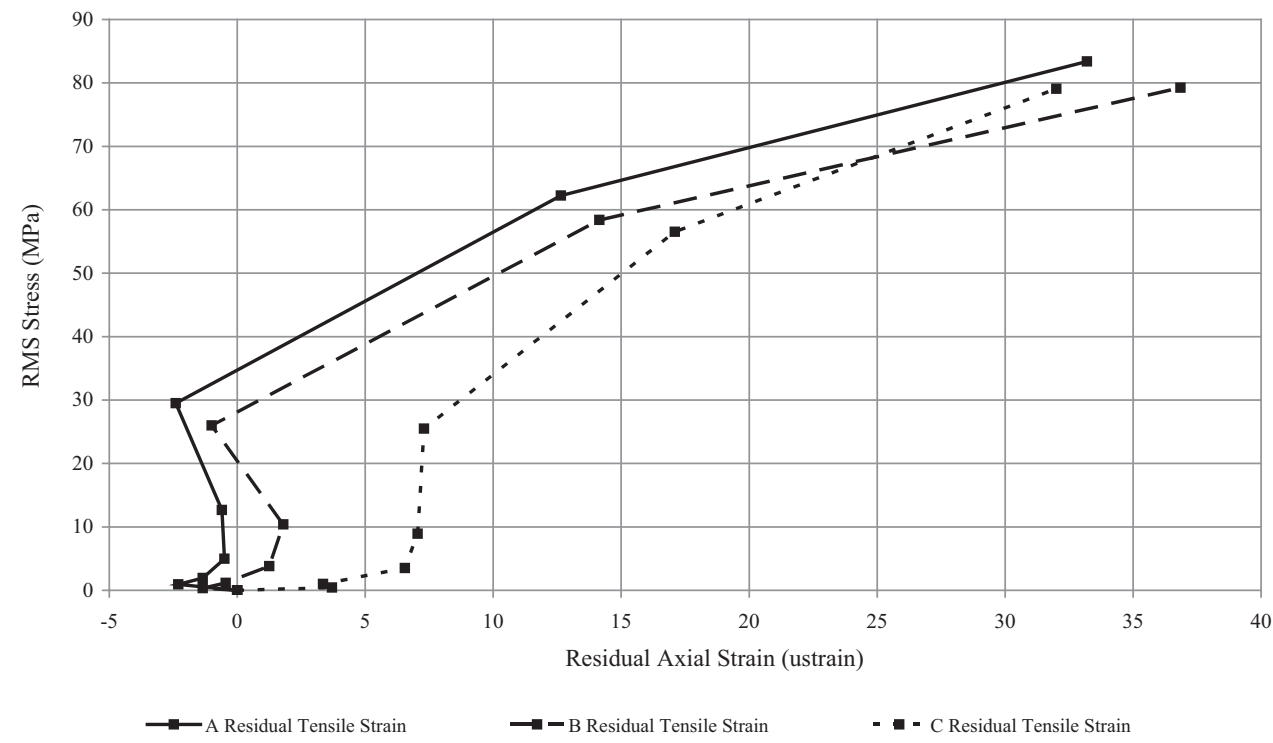

Fig. 12. Al alloy samples: RMS stress vs. residual axial (tensile) strain. 

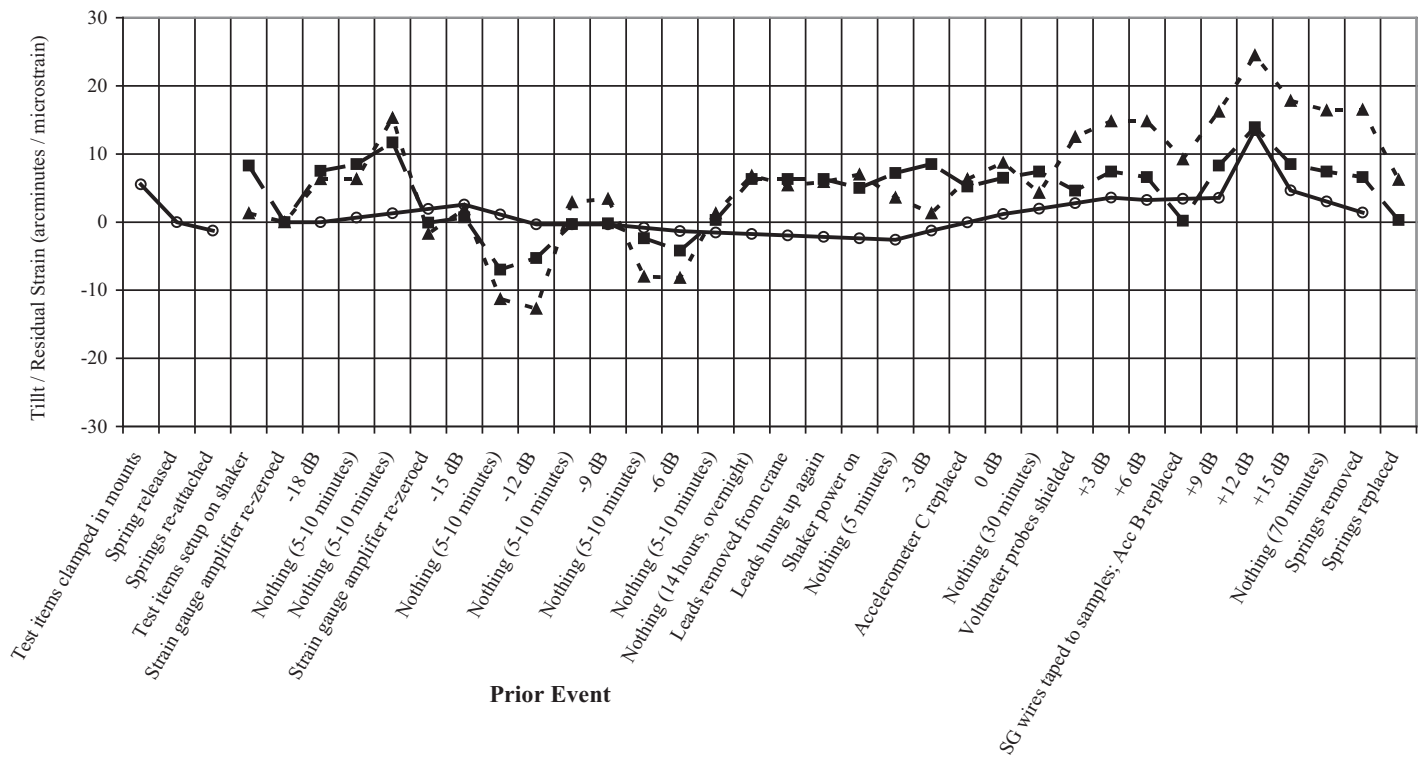

- $₫$ - Strain Gauge $1 \rightarrow$-Strain Gauge $2 \longrightarrow$ Autocollimator

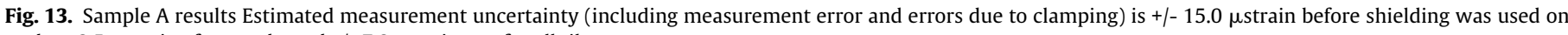
probes, $8.5 \mu$ strain afterwards, and $+/-7.8$ arcminutes for all tilt measurements.

high-noise environment around the shaker - the use of shielding significantly improved this. The autocollimator proved to be an accurate instrument for measuring residual bending, but not axial strain.

Correlation between accelerometer data and FEA was also very good, though some (upwards) adjustment of the damping factor was required to get a well-correlated model.

\subsection{Test results}

The Al alloy samples exhibited greater residual strains in tension than in bending - they effectively became slightly longer during vibration. This was a somewhat unexpected result, as FEA and hand calculations both showed that bending stresses due to the first modeshape were substantially higher than any tensile stresses that could be caused by frictional resistance at the sliding end (approximately 0.53 MPa axial stress, compared with 55.8 MPa due to bending). This was true assuming either frictional resistance at the axially floating end or the extreme case of both ends fully constrained axially (in fact the natural frequency was very close to that predicted by the FEA model with no axial constraint at the floating end). That all three samples demonstrated this effect, and it was outside the range of experimental error, suggests that it is a real effect.

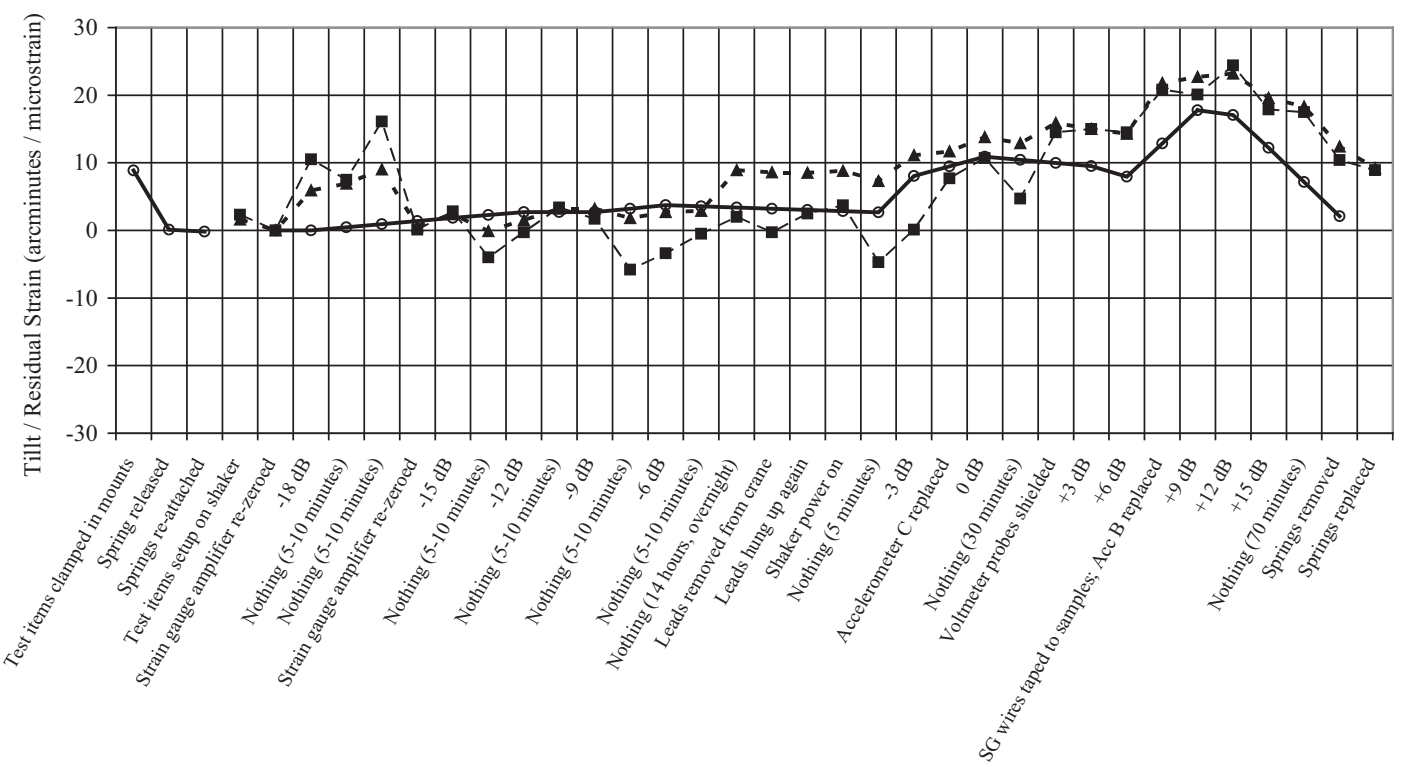

Prior Event

- \pm - Strain Gauge 1 - - - Strain Gauge $2 \longrightarrow$ - Autocollimator

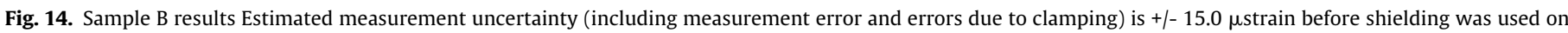
probes, $8.5 \mu$ strain afterwards, and $+/-7.8$ arcminutes for all tilt measurements. 


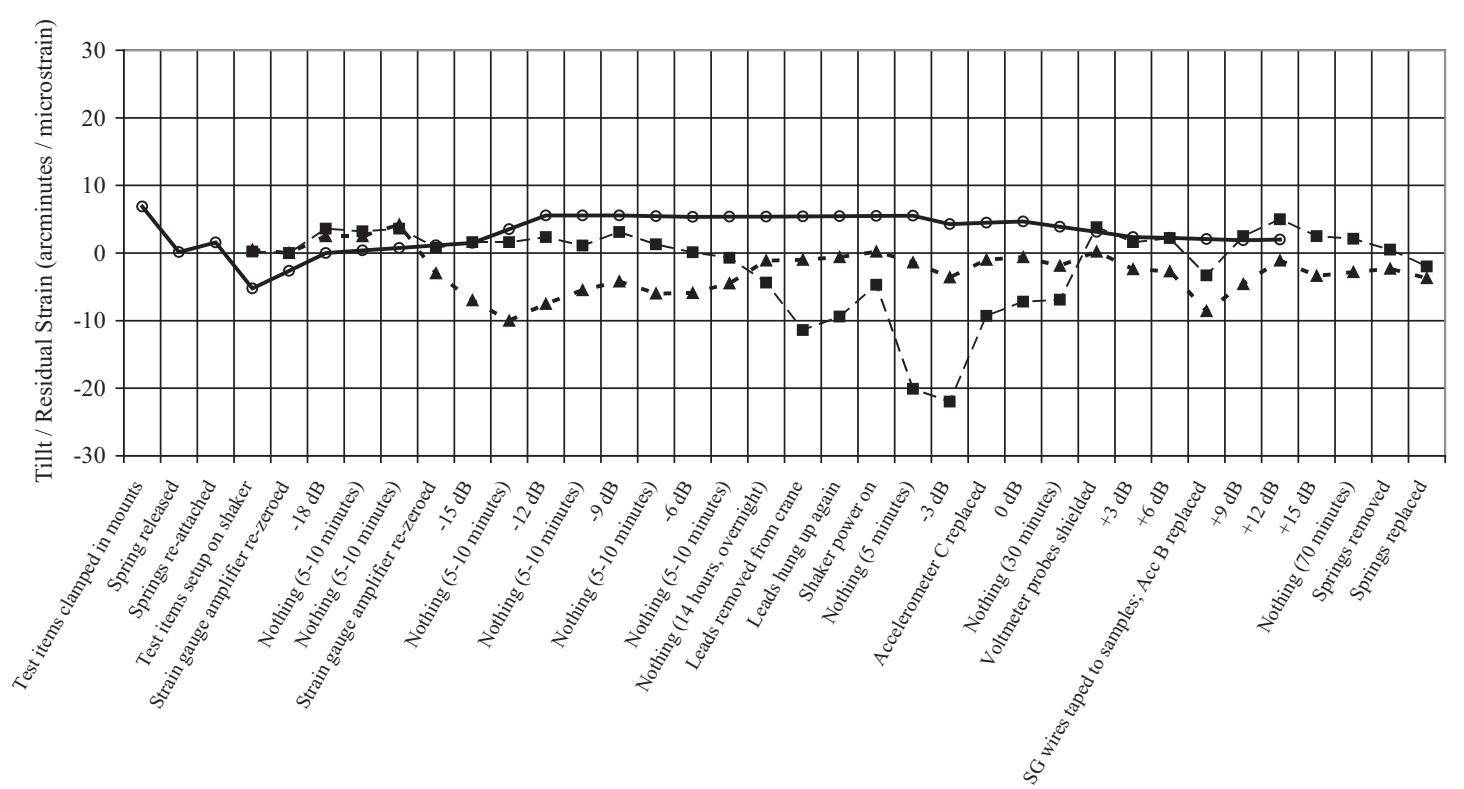

Prior Event

- $\mathbf{A}$ - Strain Gauge 1 - - Strain Gauge $2 \longrightarrow$ - Autocollimator

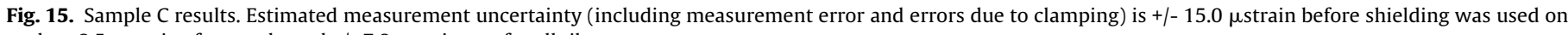
probes, $8.5 \mu$ strain afterwards, and $+/-7.8$ arcminutes for all tilt measurements.

There are several possible explanations for this. Firstly, it could be due to long-range internal stress relief. Internal stresses were not measured, though they were minimised with heat treatment. The effects seen here could also be seen if yield behaviour in tension was slightly different to that in compression. Adrien et al. [20] describe the strain differential effect (SDE), for which the stress-strain curves for a material are slightly different in tension and compression at low levels of plastic strain $(\ll 0.2 \%)$. As strain increases, the stress-strain curves converge to be the same at the strain levels of usual interest to engineers. The effect is somewhat dependent on prior strain history. For the current study, the static Al sample test showed that the side in tension exhibited higher residual strains than the side in compression.
Although this trend is consistent with the length increase observed in the dynamic tests, the SDE is a small effect, and unlikely be responsible for the large tension-bending discrepancy observed. Cyclic plasticity models that incorporate differences in tensile and compressive post yield behaviour were not available in the FEA package used however (ANSYS 12.1), so this could not be verified analytically.

A final possible explanation is that we are simply observing Shakedown, a cyclic plasticity effect due to non-symmetric loading (i.e., dynamic cyclic loads are superimposed on a static mean load). The loading non-symmetry would be due to friction at the axially free end inducing axial tension when the samples bend either upwards or downwards.

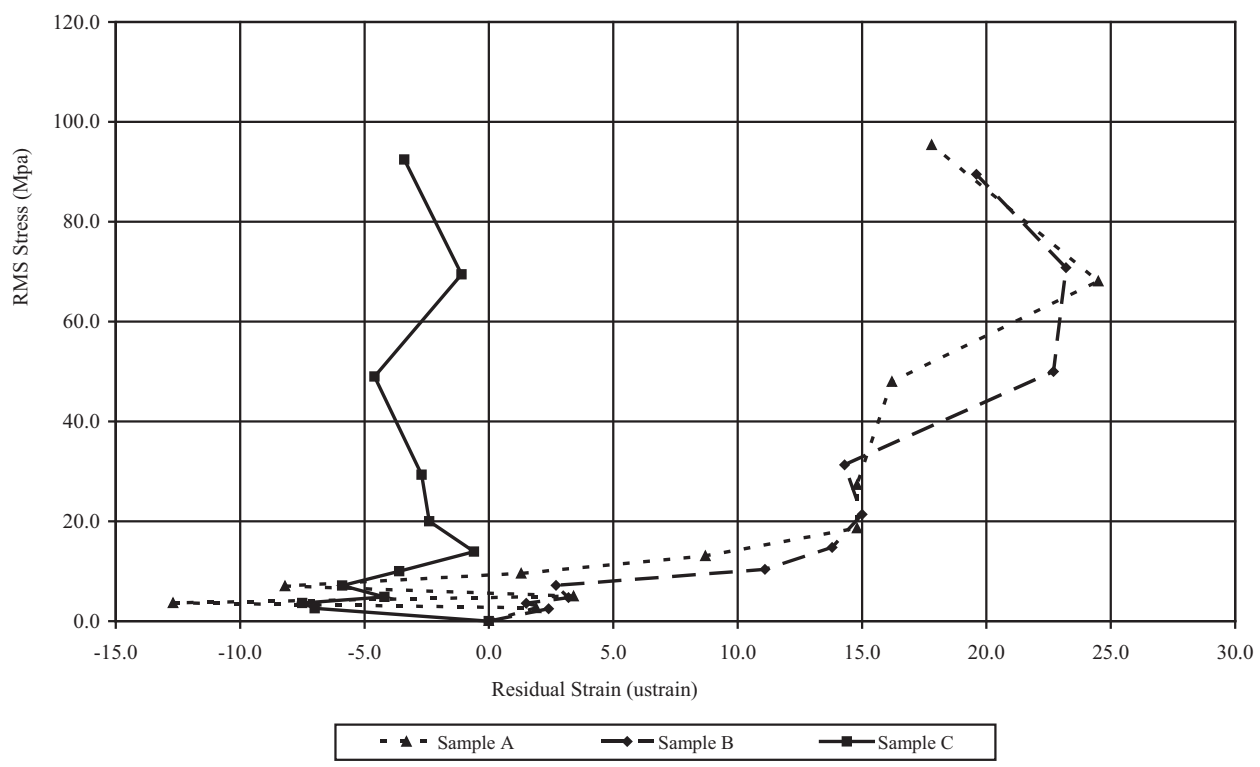

Fig. 16. Dynamic stress/strain plots for CFRP samples (centre strain gauges only). 


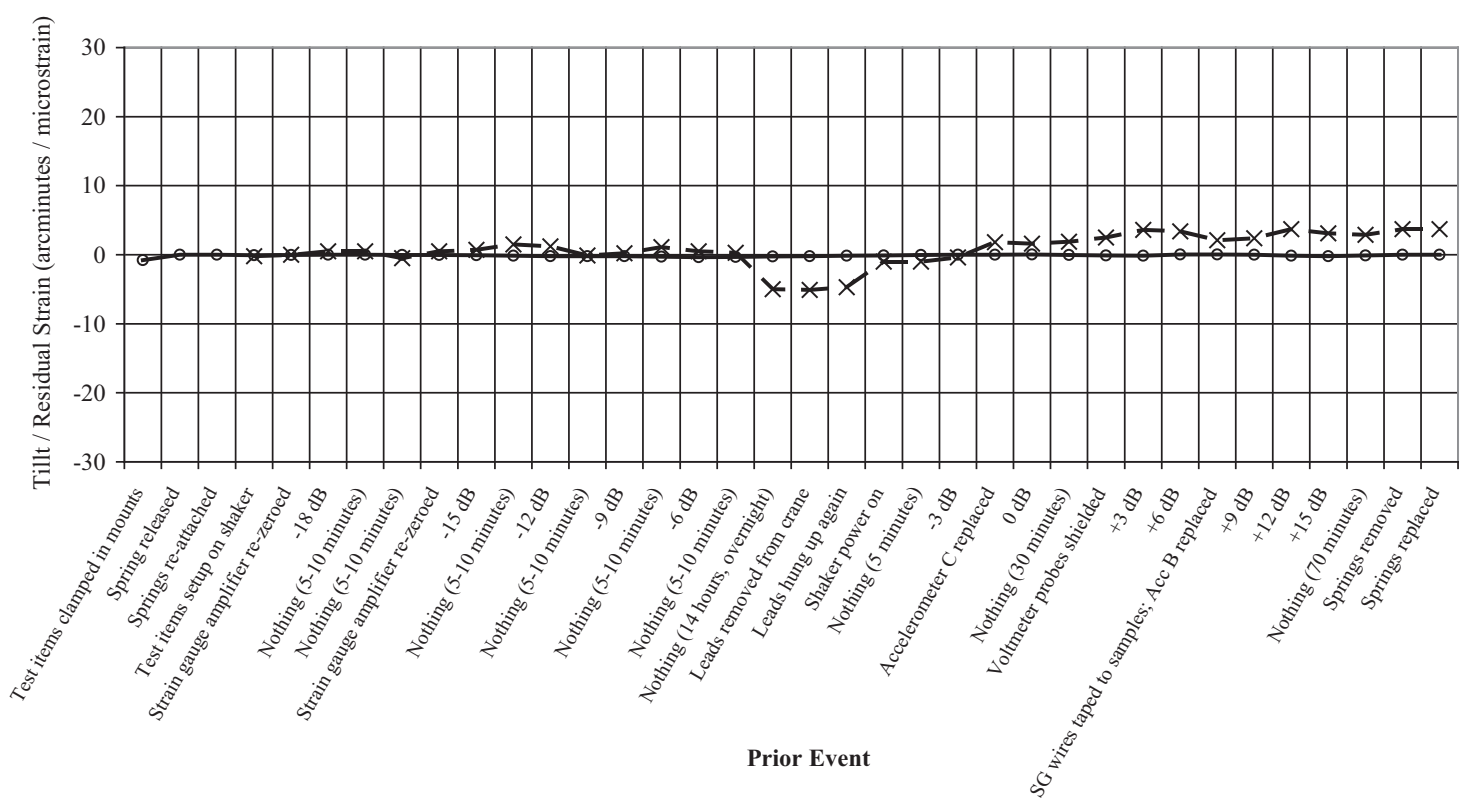

$\rightarrow \times-$ Strain Gauge $\longrightarrow$ Autocollimator

Fig. 17. CFRP control sample results Estimated error is $+/-0.3 \mu$ strain for the strain gauge, and $+/-0.17$ arcminutes for the autocollimator.

It is more difficult to draw conclusions from the CFRP tests due to the high early experimental error and the strain gauge mounting strategy. There is a clear directional response for samples A and B, suggesting again that some pre-stress or load asymmetry is present. Residual strain in this material is probably due to matrix micro-yield or transverse micro-cracking. The recovery of this strain during the last shake may be wholly due to the mounting errors investigated in Fig. 16.

\subsection{Finite element analysis}

The axial growth in sample length of the Al alloy samples was investigated further with FEA. A simple 2D model (Fig. 17) was generated incorporating nonlinear large deformation effects and solved for repeated non-symmetric load cycles in the time domain.

The nonlinear kinematic hardening rule proposed by Chaboche [21] and Lemaitre and Chaboche [4] was used. The material model used two superimposed kinematic hardening rules, each for a different strain region. The first used data from the static four point bend test results shown in Fig. 10, for a low strain range. The second was from a study by Francois [22] for a similar material (alloy 2024 T4) in a relatively high range of plastic strain. The constants used are given in Table 3. Here, $k$ is the elastic limit, $C_{i}$ are initial hardening moduli for stain ranges of interest, and $\gamma_{i}$ are parameters that describe the rate of change of hardening modulus with plastic strain. It should be noted that these constants were determined from monotonic loading data - ideally data from evolved hysteresis

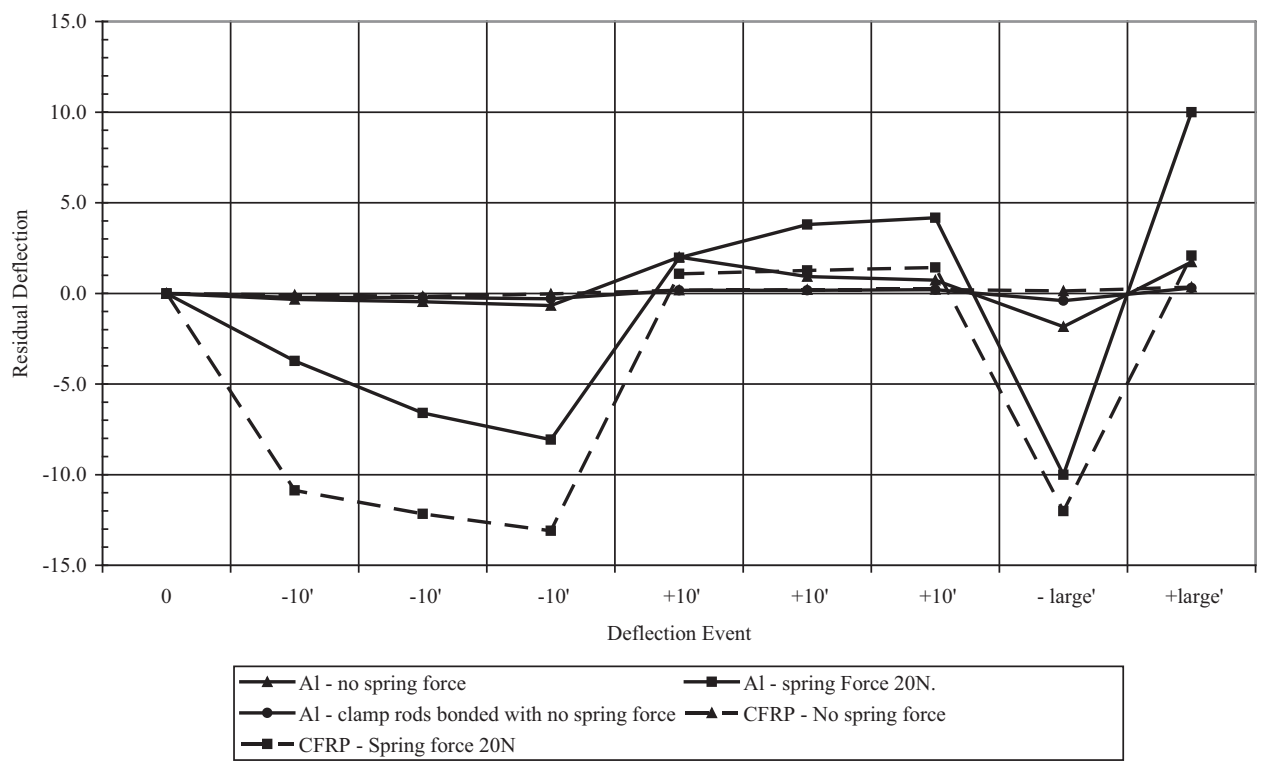

Fig. 18. Measurements of experimental errors due to mounting. 
Table 3

Nonlinear kinematic hardening constants.

\begin{tabular}{lll}
\hline Constant & Value & Units \\
\hline$k$ & $4.37 \mathrm{e} 7$ & $\mathrm{~Pa}$ \\
$C_{1}$ & $1.94 \mathrm{e} 12$ & $\mathrm{~Pa}$ \\
$\gamma_{1}$ & 6748 & - \\
$C_{2}$ & $1.18 \mathrm{e} 10$ & $\mathrm{~Pa}$ \\
$\gamma_{2}$ & 103 & - \\
\hline
\end{tabular}

loops would have been used to describe cyclic plasticity, although this was not available.

The $+12 \mathrm{~dB}$ (58.4 MPa RMS) test was used for analysis, as this was the first load case that produced significant residual strain events, with roughly similar results for samples A and B. Firstly, the FEA model was correlated with the test results by adjusting the damping values for each mode. Correlation was based on the accelerometer response for sample B (see Fig. 18). The responses are well correlated for the first two modes, but not after this (the difference in high frequency behaviour is probably due to the FEA model being only two-dimensional).

While the test response in Fig. 18 shows significant peaks well beyond the first natural frequency, these peaks are less of a concern for stress analysis. This is because the resulting displacements (and therefore the stresses and strains) are inversely proportional to the square of the frequency. The power-spectral density response for one of the strain gauges on sample B is shown in Fig. 19 to illustrate this.

To determine the quasi-static load to be applied, it was assumed that the residual strain response was entirely due to the first bending mode of the samples, with no contribution from the higher modes. The response due to the first mode only was obtained by truncating the full response at a factor of 1.414 from the first natural frequency. The RMS value of this truncated response was then used as a quasi-static input acceleration for the time-domain analyses. The FEA-determined RMS stress response at the centre of the

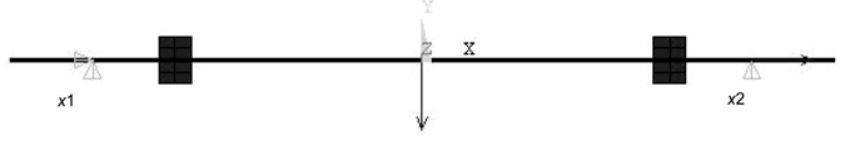

Fig. 19. Al alloy sample FEA model.

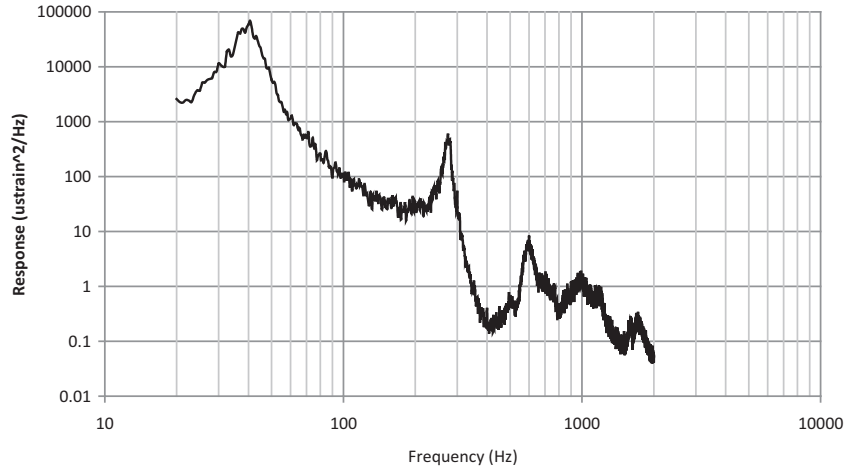

Fig. 21. Power spectrum of the microstrain response for the sample $B+12 \mathrm{~dB}$ run.

sample compared well with the RMS value measured by the strain gauges (56.2 and $58.2 \mathrm{MPa}$, respectively).

The load non-symmetry was provided by an axial frictional force at the axially free end. Friction was measured directly from the test rigs with a force transducer to have static coefficient of 0.376 . The axial frictional load was applied at point $x 2$ in Fig. 17, and was based on the sum of the resultant force at this point and the spring clamping force.

Next, the cyclic plasticity analyses were performed by applying a series of bending load cycles, applied as quasi-static accelerations. A Miner's Rule approach was taken, assuming there would be contributions from stress cycles over a range of amplitudes. Accelerations were determined at the 1- $\sigma, 2-\sigma$ and 3- $\sigma$ levels, with the number of cycles commensurately determined from the probability of exceedance to be 779,112 and 7, respectively (based on the test duration and frequency of the first mode). Each full load cycle used two load steps, with a number intermediate of sub-steps. For ease of generation of the load step input files, the cycles were applied in groups of the same level - i.e., the 3- $\sigma$ cycles were applied first, followed by the $2-\sigma$ and $1-\sigma$ cycles.

The results are shown in Fig. 20 for the time-domain plastic strain response. There is a clear trend from equal tensile and compressive plastic strains in the first cycle to purely tensile residual strains at the end of all cycles. Fig. 21 shows this behaviour with stress vs. plastic strain hysteresis curves. These commence with the 7 large 3- $\sigma$ cycles, followed by the 2- $\sigma$ and finally the $1-\sigma$ cycles. By the time the $1-\sigma$ cycles are complete, both the tension and

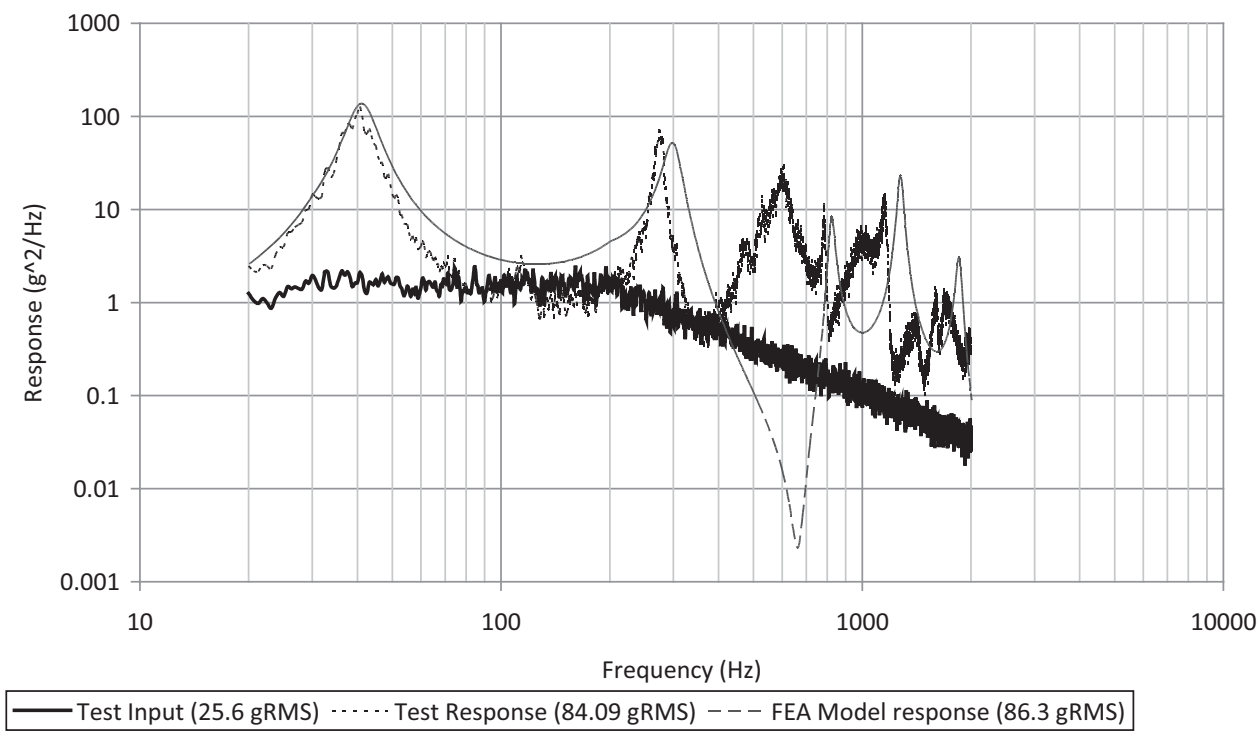

Fig. 20. Al alloy sample $\mathrm{B}+12 \mathrm{~dB}$ run - correlation between accelerometer data and FEA model. 


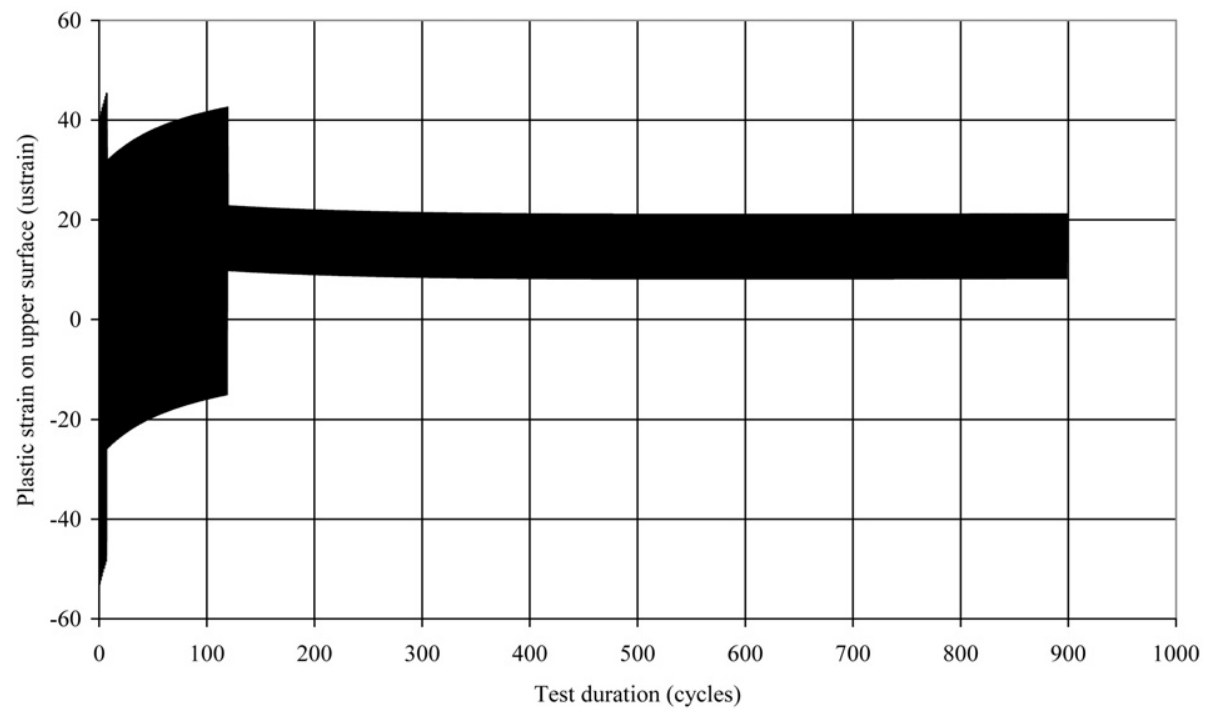

Fig. 22. Plastic strain results at upper surface node representing a strain gauge.

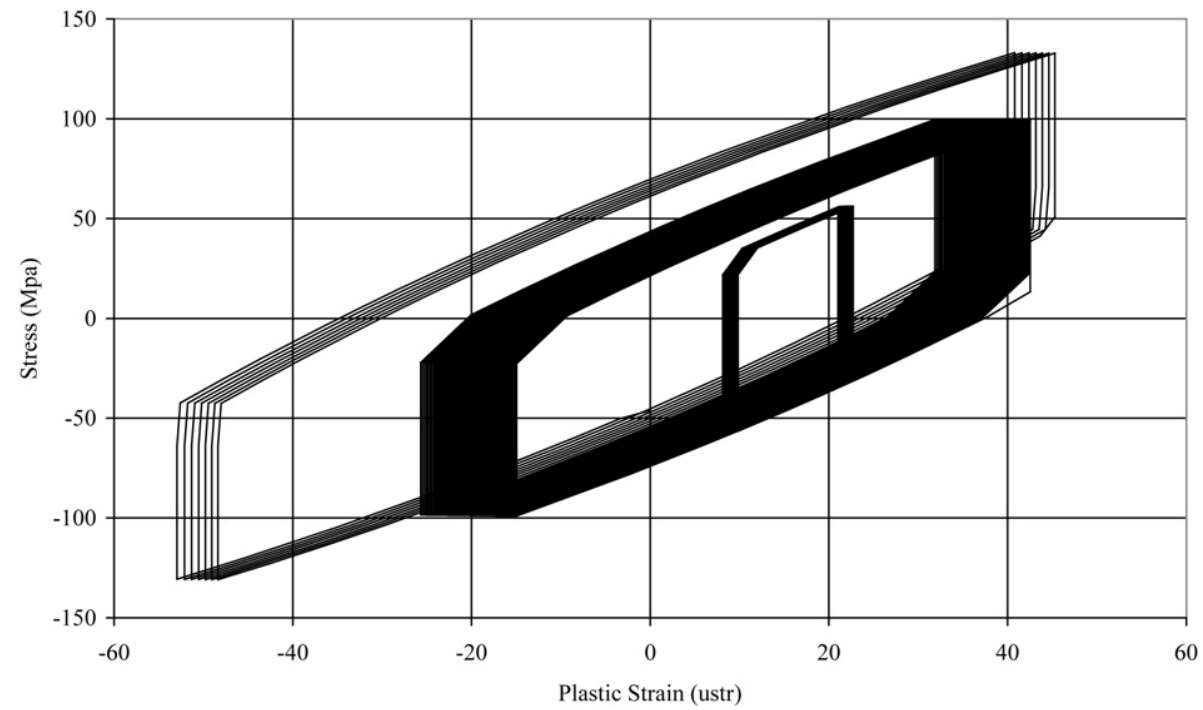

Fig. 23. Stress vs plastic strain hysteresis curves for the analysis.

compression sides of the cycles are on the residual tensile strain (positive) side of the graph, indicating an overall elongation of the sample. The final values were $21.1 \mu$ strain and $8.2 \mu$ strain on the upper and lower surfaces respectively, giving an average axial extension of $14.7 \mu$ strain. The equivalent values observed with strain gauges for sample B during the $+12 \mathrm{~dB}$ test were of $27.2 \mu$ strain and $3.1 \mu$ strain, giving an average of $15.2 \mu$ strain.

Figures 22 and 23.

Thus this simple FEA model has been able to predict the extension behaviour of this sample with reasonable accuracy. The difference between the final upper and lower values is dependent on the amplitude of the final stress cycle applied, in this case 1- $\sigma$. The test results suggest that a final cycle of slightly more than 1- $\sigma$ would have been appropriate for the FEA model.

The peak stresses seen in the material, about $130 \mathrm{MPa}(3-\sigma)$, are of a level that may potentially occur in a spacecraft structure. Such structures are often dimensioned using gross structural failure based on UTS and $0.2 \%$ proof strength as failure criteria. These values are over 400 and $300 \mathrm{MPa}$, respectively, and likely to provide positive safety margins in this case.
It should be noted that the nonlinear kinematic hardening rule used here is based on von Mises equivalent stresses. The use of von Mises stresses with random vibration analysis can be problematic as they do not follow a normal distribution (see Section 1). For the analysis presented here, the simple geometry and loading means that the peak von Mises stresses are nearly identical to the peak component (X-direction in Fig. 17) stresses, which are Gaussian. For more complex analyses, other methods would be required to estimate the number of cycles at each stress level.

\section{Conclusion}

A novel test rig has been developed to assess the residual strain response of materials subjected to random vibration. The rig makes use of a four-point bend setup mounted on an electro-dynamic shaker. A number of refinements were made to the test setup to tackle electronic noise from the shaker armature and other sources of experimental error. It is proposed that the final setup used is adequate for future work in this area. 
Data for an Al alloy and a CFRP composite were gathered. The test results clearly show that random vibration can cause dimensional instability in both composite and metallic materials. The results for the metallic samples were found to be substantially "sided", with a relatively low degree of non-symmetry in the load having a large directional effect on plastic strain response. Another substantial contribution of this article is to prove that this behaviour can be modelled with reasonable accuracy using a time-domain FEA model with cyclic plasticity properties based on static test data.

This finding has implications for ultra-stable structures such as mirror mounting flexures, which are usually metallic. Ideally, such structures should be assembled in a completely strain-free manner. Even if this is possible, loading non-symmetry will result from vibration exposure in a $1 g$ environment. For satellites, the structure will see an additional static acceleration of several $g$ during the launch phase. The asymptotic behaviour of the plastic strain response curve of Fig. 20 suggests that "bedding-in" vibrations applied to structures during optical alignment operations may be a useful approach to minimising the risk of vibration-induced dimensional instability once deployed.

\section{References}

[1] Marschall CW, Maringer RE. Dimensional instability - an introduction. Oxford, New York, Toronto, Sydney, Paris, Frankfurt: Permagon Press; 1977.

[2] Paquin RA. Dimensional instability in materials: how critical is it in the design of optical instruments? SPIE Proceedings. 1992. p. CR43.

[3] Vukobratovich D. Rugged yet lightweight: how can we achieve both in optical instruments? SPIE Proceedings. 1992. p. CR-43.

[4] Lemaitre J, Chaboche J-L. Mechanics of solid materials. Cambridge, UK: Cambridge University Press; 1990.

[5] Abusafieh A, Federico D, Connell S, Cohen E, Willis PB. Dimensional stability of CFRP composites for space based reflectors. In: SPIE Proceedings, vol. 4444. 2001.
[6] Kim RY, Crasto AS, Schoeppner GA. Dimensional stability of composite in a space thermal environment. Composites Science and Technology 2000;60:2601.

[7] Cabeza I, Pradier A. Dimensional stability verification of an optical bench for space applications under thermal-vacuum environment. ESA-SP-386; 1996. p. 353.

[8] Wolff EG. Introduction to the dimensional stability of composite materials Lancaster, PA, USA: Destech Publications Inc.; 2004.

[9] Nairn JA. Matrix microcracking in composites. Comprehensive composite materials. Oxford, UK: Elsevier; 2000. Ch. 2.12.

[10] Gama BA, Lopatnikov SL, Gillespie Jr JW. Hopkinson bar experimental technique: a critical review. Applied Mechanics Reviews 2004;57(4).

[11] Nicholas T. Dynamic tensile testing of structural materials using a split Hopkinson bar apparatus. Wright-Patterson Aeronautical Laboratories Report AFWAL-TR-80-4053.

[12] Wolff EG, Crane ST. Prediction of the microyield strength of polymer matrix composites. Journal of Composites Technology and Research 1988;10(Pt 4).

[13] Steinberg DS. Vibration analysis for electronic equipment. New York, USA: John Wiley \& Sons Inc.; 2000.

[14] Gupta S, Manohar CS. Probability distribution of extremes of von Mises stress in randomly vibrating structures. Journal of Vibration and Acoustics 2005; 127.

[15] Segalman D, Reese G, Field Jr R, Fulcher C. Estimating the probability distribution of von Mises stress for structures undergoing random excitation. Transactions of the ASME 2000;122.

[16] De la Fuente E. Von Mises stresses in random vibration of linear structures. Computers and Structures 2009;87(21-22).

[17] ECSS-E-10-03A. Space engineering - testing. Noordwijk, The Netherlands: ESA European Space Research and Technology Centre; 2002.

[18] Edeson RL, Morris N, Aglietti GS, Tatnall ARL. Dimensional stability testing of a space optical bench structure. AIAA Journal 2009;47(1).

[19] Maringer RE, Cho MM, Holden FC. Stability of structural materials for spacecraft application: final report. NASA-CR-97844, 1968.

[20] Adrien J, Maire E, Estevez R, Ehrstrom JC, Warner T. Influence of the thermomechanical treatment on the microplastic behaviour of a wrought $\mathrm{Al}-\mathrm{Zn}-\mathrm{Mg}-\mathrm{Cu}$ alloy. Acta Materialia 2004;52:1653-61.

[21] Chaboche J-L. On some modifications of kinematic hardening to improve the description of ratchetting effects. International Journal of Plasticity 1991;7:661-78.

[22] Francois MLM. A pasticity model with yield surface distortion for non proportional loading. International Journal of Plasticity 2001;17(5):703-18. 